\title{
Cholesterol improves the transfection efficiency of polyallylamine as a non-viral gene delivery vector
}

\author{
Reza Kazemi Oskuee, ${ }^{1,2}$, Mahdieh Ramezanpour ${ }^{3}$, Leila Gholami ${ }^{4}$, Bizhan Malaekeh-Nikouei ${ }^{5 *}$
}

\begin{abstract}
${ }^{1}$ Targeted Drug Delivery Research Center, Mashhad University of Medical Sciences, Mashhad, Iran, ${ }^{2}$ Department of Medical Biotechnology, School of Medicine, Mashhad University of Medical Sciences, Mashhad, Iran, ${ }^{3}$ School of Pharmacy, Mashhad University of Medical Sciences, Mashhad, Iran, ${ }^{4}$ Neurogenic Inflammation Research Center, Mashhad University of Medical Sciences, Mashhad, Iran, ${ }^{5}$ Nanotechnology Research Center, School of Pharmacy, Mashhad University of Medical Sciences, Mashhad, Iran
\end{abstract}

\begin{abstract}
Cationic polymers such as polyallylamine (PAA) having primary amino groups are poor transfection agents and possess a high cytotoxicity index when used without any chemical modification. In this study, PAA was modified with cholesterol in order to improve transfection efficiency and to reduce cytotoxicity. PAA polymers with molecular weights of 15 and $65 \mathrm{kDa}$ were selected and grafted with cholesterol at percentages of 5, 10, 15,30, and 50. After purification, the efficacy of the synthetic vectors was evaluated in terms of DNA condensation using the ethidium bromide test, buffering capacity, particle size, zeta potential, transfection efficiency, and cytotoxicity assay in Neuro2A cell lines. According to the ethidium bromide test, these vectors can condense DNA at moderate and high carrier to plasmid $(\mathrm{C} / \mathrm{P})$ ratios. The buffering capacity of the prepared vector in both molecular weights was less than unmodified PAA. Particle size measurements demonstrated that modified PAAs were able to form nanoparticles ranging in size from 125 to $530 \mathrm{~nm}$. The vectors based on PAA $15 \mathrm{kDa}$ demonstrated a better transfection efficiency than the vectors made of PAA $65 \mathrm{kDa}$. Cytotoxicity studies showed that toxicity of all vectors was less than PAA. Some cholesterol modified polymers composed of PAA (15 kDa) were suitable vectors for gene delivery with low cytotoxicity.
\end{abstract}

Keywords: Cholesterol/ efficiency. Gene delivery. Non-viral vectors/evaluation. Polyallylamine Transfection efficiency. Cytotoxicity/study.

\section{INTRODUCTION}

Research in recent years has witnessed major concern about gene therapy providing novel approaches to the treatment of many diseases caused by genetic disorders (Guo et al., 2008). The delivery of nucleic acids to target cells and tissues, despite all achieved advances, still remains challenging (Li, Huang, 2000; Chesnoy, Huang, 2000). Specifically, gene therapy pursues the development of non-toxic effective gene carrier encapsulating and carrying foreign genetic materials into specific cell types including cancerous cells (El-Aneed, 2004).

Gene delivery carriers are generally divided into two major groups named viral and non-viral vectors (Liu,

\footnotetext{
*Correspondence: B. Malaekeh-Nikouei. School of Pharmacy, Mashhad University of Medical Sciences, P.O. Box 91775-1365 - Mashhad, Iran. Phone: 98 5138823255 / Fax: 98513 8823251. E-mail: malaekehb@mums.ac.ir
}

Huang, 2002). Each of these vectors demonstrates its own advantages and drawbacks (Cusack, Tanabe, 2002). Many deficiencies in several areas including the induction of host inflammatory and immune response are reported for viral vectors, though they provide high gene delivery efficiency (Tros-de-Ilarduya, Sun, Duzgunes, 2010). Nonviral vectors, especially polymers, show remarkably lower safety risks that can be applied for specific therapeutic purposes. Their most specific feature is being capable of carrying large DNA molecules and being produced most cost-effectively and in large quantity (Dehshahri et al., 2014). However, low transfection efficiency remains the major drawback of non-viral systems (Merdan, Kopecek, Kissel, 2002).

Polyallylamine (PAA) possessing a high density of primary amino groups (as free amino or as cationic ammonium salts) has recently attracted much attention as a non-viral gene delivery system (Nimesh, Kumar, Chandra, 
2006; Boussif et al., 1999). Negatively charged DNA can be bound and packaged by PAA carrying a strong positive charge. However, PAA application as a gene delivery system has severely been restricted by cytotoxicity of PAA that is due to its strong polycationic character (Pathak et al., 2007). The lack of provision of endosomal escape resulting from the low buffering capacity of PAA is another disadvantage of this polymer (Pathak, Patnaik, Gupta, 2009). Numerous modifications have been carried out on this polymer to make it an effective and non-toxic carrier, including the preparation of nanocomplexes composed of PAA-dextran-DNA with an average size of about 150 nm, by Nimesh, Kumar, and Chandra (2006). Compared to the PAA-DNA nanoparticles, the evaluation of transfection efficiency of the prepared nanoparticles in HEK 293 cells showed an increase in the transfection efficiency and decrease in cytotoxicity. Moreover, in order to improve the endosomal release and enhance the gene transfer efficiency of the polymer, Pathak, Patnaik, and Gupta (2009) replaced primary amino groups of PAA (17 $\mathrm{kDa}$ ) with imidazolyl moieties. Recently, we modified PAA with bromoalkane derivatives (Oskuee et al., 2015a) and acrylate derivatives (Oskuee et al., 2015b). Better transfection activity and less cytotoxicity were observed in some of the prepared vectors.

The present study aims at enhancing PAA transfection efficiency through replacing primary amino groups with cholesterol, reducing the polymer cytotoxicity, developing polymer hydrophobic interaction with the cell membrane, and maintaining the polymer buffering capacity. It is expected that as nanoparticles cross the cell membrane, vector release from the endosome becomes easier (through endosome membrane instability) and polymer toxicity decreases.

\section{MATERIALS AND METHODS}

\section{Materials}

Dimethylformamide, cholesterol chloroformate and [3-(4,5-dimethylthiazol-2-yl)-2,5-diphenyl tetrazolium bromide] (MTT) were purchased from Sigma (USA). PAA (average MW $15 \mathrm{kDa}$ ) and PAA (average MW $65 \mathrm{kDa}$ ) were obtained from Polyscience Inc. (USA) and Aldrich (USA), respectively.

\section{Modification of PAA}

For the preparation of PAA-cholesterol conjugates, both were dissolved separately in dimethylformamide. A solution of cholesteryl chloroformate was drop-wised to the stirring solution of PAA over 2 hours. The reaction was stirred for 24 additional hours at room temperature. The resulting solution was poured into a dialysis membrane $(10 \mathrm{kDa}$ cut-off dialysis tubing for derivate of PAA $15 \mathrm{kDa}$ and $25 \mathrm{kDa}$ cut-off dialysis tubing for derivate of PAA 65 $\mathrm{kDa}$ ) and dialyzed against double distilled water for 2 days to remove unreacted material. The aqueous solution was lyophilized to yield fluffy powders that were characterized by ${ }^{1} \mathrm{HNM}$ (DMSO) spectroscopy using a Bruker Avance III-300 MHz NMR spectrometer (Bruker, Germany).

\section{Determination of the degree of grafting percent by TNBS}

The primary amine content of modified PAA derivatives was determined using quantification of accessible primary amines through coupling with 2,4,6-trinitrobenzene sulfonic acid (TNBS) (Snyder, Sobocinski, 1975). Briefly, $20 \mu 1$ of freshly prepared aqueous TNBS solution $(15 \mathrm{mg} / \mathrm{ml})$ was added to the wells of a 96-well tray containing various amounts of modified PAA (dissolved in $600 \mu \mathrm{l}$ of double distilled water). The mixtures were diluted with $200 \mu$ l of sodium bicarbonate buffer solution ( $0.8 \mathrm{M}, \mathrm{pH} 8.5)$ and the UV absorbance was measured at $405 \mathrm{~nm}$.

\section{Measurement of buffering capacity of modified PAA}

A solution of $0.4 \mathrm{mg} / \mathrm{ml}$ of each PAA derivative in double distilled water was prepared and adjusted to the $\mathrm{pH}$ of 12 using $1 \mathrm{M} \mathrm{NaOH}$. Then, $5 \mu \mathrm{l}$ aliquots of $1 \mathrm{M} \mathrm{HCl}$ were subsequently added until the $\mathrm{pH}$ was reduced to 2 . The reciprocal slopes of graphs plotting $\mathrm{pH}$ versus the amount of $\mathrm{HCl}$ added were used to determine the buffering capacity of PAA derivatives.

\section{Preparation of polyplexes}

For preparation of polyplexes, different amounts of PAA derivatives were separately diluted into the HEPES buffered glucose solution (20 mM HEPES in 5\% aqueous glucose solution) and mixed with pDNA at different carrier to pDNA weight ratios $(\mathrm{C} / \mathrm{P})$ ranging from $0.5: 1$ to $6: 1$. The mixture was incubated at room temperature for 30 min before use.

\section{Characterization of polyplexes}

The mean size and zeta potential of nanocomplexes were determined using a particle size analyzer (Zetasizer 
NanoZS, Malvern Instruments, UK). Condensation ability of cholesterol modified PAA was examined by the ethidium bromide $(\mathrm{EtBr})$ test. This DNA-intercalating dye was used to examine the association of DNA with the modified polymer. The fluorescence intensity of this dye was measured at $510 \mathrm{~nm}$ (excitation wavelength) and $590 \mathrm{~nm}$ (emission wavelength) with a spectrofluorometer (Jasco, Japan). The fluorescence intensity was set to $100 \%$. Equal amounts of the solution containing modified PAA were added stepwise to the pDNA-EtBr solution and the variation in fluorescence intensity was recorded. All measurements were done in triplicate.

\section{Gene transfer studies}

Neuro2A murine neuroblastoma cells (ATCC CCL131) were cultured in Dulbecco's Modified Eagle Medium (DMEM) supplemented with fetal bovine serum (10\%), streptomycin $(100 \mu \mathrm{g} / \mathrm{ml})$, and penicillin $(100 \mathrm{U} / \mathrm{ml})$. Cells were seeded at a density of $1 \times 10^{4}$ cells per well in 96-well plates. Polyplexes were prepared in $\mathrm{C} / \mathrm{P}$ ratios of $0.5,2$, 4 , and 6 and added to the cells. After $4 \mathrm{~h}$ incubation, the medium was removed and replaced with fresh medium. Cells were harvested $24 \mathrm{~h}$ post transfection and lysis buffer was added to each well. The percentage of transfected cells was determined using a fluorescent plate reader (Victor X5, Perkin- Elmer, USA). Green fluorescent protein (GFP) fluorescence was excited at $498 \mathrm{~nm}$ and emission was detected using a $535 \mathrm{~nm}$ band-pass filter. Polyethyleneimine (PEI) $25 \mathrm{kDa}$ was used as positive control.

\section{Cytotoxicity assay by MTT}

Cytotoxicity studies were carried out in Neuro2A cells using polymer/pDNA complexes. $1 \times 10^{4}$ cells per well were seeded in 96-well plates and treated after $24 \mathrm{~h}$ with the same amounts of polyplexes used for transfection experiment. After $4 \mathrm{~h}$, the medium was replaced by $100 \mu \mathrm{l}$ fresh culture medium. The metabolic activity of each well was determined after $24 \mathrm{~h}$ using MTT assay as follows: $10 \mu \mathrm{l}$ of a $5 \mathrm{mg} / \mathrm{ml}$ solution of MTT in sterile phosphatebuffered saline buffer was added to each well. After incubation for $2 \mathrm{~h}$ at $37^{\circ} \mathrm{C}$, the medium was removed, $100 \mu 1$ of dimethyl sulfoxide added, and the samples further incubated at $37^{\circ} \mathrm{C}$ for $30 \mathrm{~min}$ under constant shaking. Optical absorbance was measured at $590 \mathrm{~nm}$ (reference wavelength $630 \mathrm{~nm}$ ) using a microplate reader (Statfax-2100; Awareness Technology, USA), and cell viability was expressed as a percent relative to untreated control cells. Values of metabolic activity are presented as mean \pm SD of triplicates.

\section{Statistical analysis}

We used one-way ANOVA and the Tukey-Kramer test to analyze our data. Differences between means were statistically significant if the p-value was less than 0.05 .

\section{RESULTS}

Cholesterol was grafted on 15 and $65 \mathrm{kDa}$ PAA primary amines in different degrees of substitutions. The compositions of the modified polymers were confirmed by ${ }^{1} \mathrm{H}$ NMR. As an example, the obtained data from ${ }^{1} \mathrm{H}$ NMR (DMSO) spectrum of PAA15-Chol (15\%) was: $0.65(\mathrm{~s}, 3 \mathrm{H}, \mathrm{CH} 3), 0.84(\mathrm{~d}, 6 \mathrm{H}, \mathrm{J}=6.0,2 \times \mathrm{CH} 3), 0.91$ (d, 3H, J = 6.0, CH3), 0.94 (s, 3H, CH3), 0.84-1.53 (m, $23 \mathrm{H}), 1.61-2.3(\mathrm{~m}, 7 \mathrm{H}), 3.2-3.6(\mathrm{~m}, \mathrm{NCH} 2), 4.63-4.65$ $(\mathrm{m}, 1 \mathrm{H}), 5.27(\mathrm{~d}, 1 \mathrm{H})$. TNBS assay was done to determine the amount of primary amines of the modified polymers and the coverage of primary amines with cholesterol. As summarized in Table I, the degree of substitution was near to initial reaction feed.

TABLE I - Degree of primary amine substitution in cholesterol modified polyallylamine (PAA) (15 and $65 \mathrm{kDa})$ estimated by TNBS assay

\begin{tabular}{lcc}
\hline Samples & $\begin{array}{c}\text { Initial reaction } \\
\text { mole \% }\end{array}$ & $\begin{array}{c}\text { Calculated \% of } \\
\text { primary amine } \\
\text { substitution by } \\
\text { cholesterol }\end{array}$ \\
\hline PAA15-Chol (5\%) & 5 & 3.2 \\
PAA15-Chol (10\%) & 10 & 9.3 \\
PAA15-Chol (15\%) & 15 & 16.2 \\
PAA15-Chol (30\%) & 30 & 24.6 \\
PAA15-Chol (50\%) & 50 & 52.2 \\
PAA65-Chol (5\%) & 5 & 6.0 \\
PAA65-Chol (10\%) & 10 & 13.2 \\
PAA65-Chol (15\%) & 15 & 15.4 \\
PAA65-Chol (30\%) & 30 & 29.1 \\
PAA65-Chol (50\%) & 50 & 52.3 \\
\hline
\end{tabular}

The results of acid-base titration studies were presented in Figure 1. This test was performed to assess the buffering capacity of modified polymers. Because of the relationship between the efficiency of polymer to facilitate endosome escape, this test was done on all samples. As indicated by results of Figure 1, cholesterol grafted PAA was led to a reduction of buffering capacity for both molecular weights of PAA. 

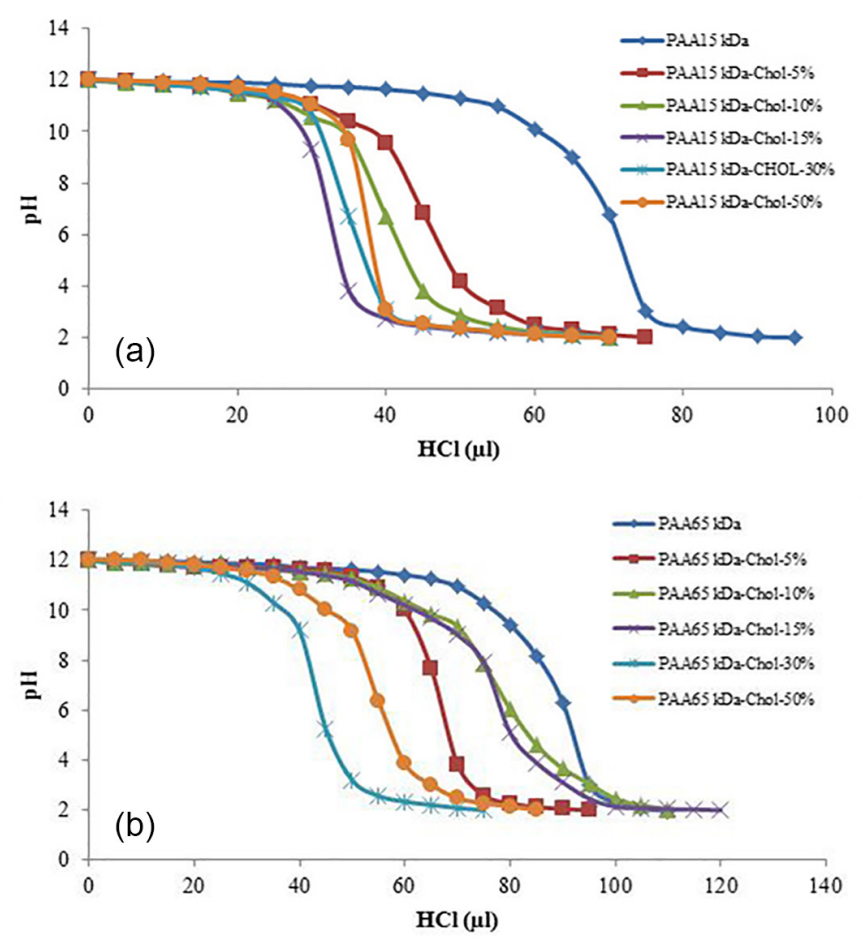

FIGURE 1 - Buffering capacity of A) polyallylamine (PAA) 15 KDa derivatives, B) PAA 65 KDa derivatives.

The particle size and zeta potential of polyplexes were summarized in Table II. The particle sizes of all polyplexes prepared with modified cholesterol were found to be in the range of $125-530 \mathrm{~nm}$. As the cholesterol content was increased, a concomitant increase in the size of the nanoparticles was observed. The vectors based on PAA $15 \mathrm{kDa}$ had positive zeta potential. Only in the case of PAA with $50 \%$ grafting, polyplex showed negative zeta-potential. All vectors based modified PAA $65 \mathrm{kDa}$ had negative surface charge.

Both 15 and $65 \mathrm{kDa}$ PAAs condensed the pDNA at $\mathrm{C} / \mathrm{P}$ ratio of 0.5 (Figure 2). The interaction of DNA and synthetic polymers by substitution was decreased. The
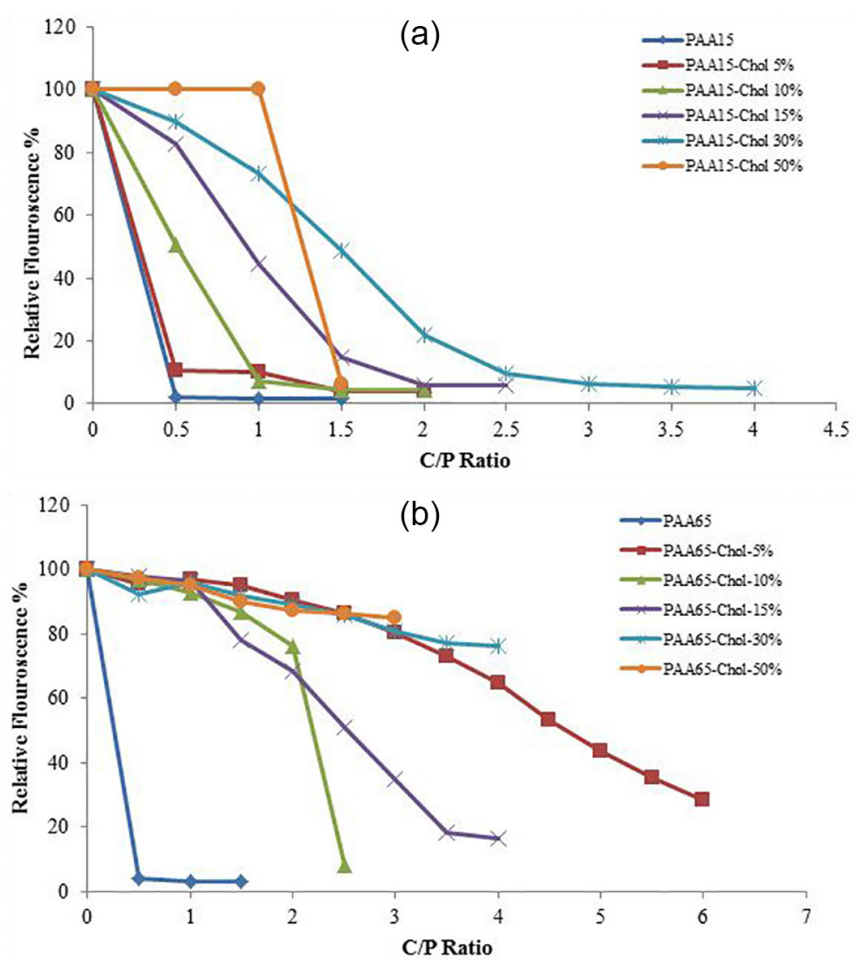

FIGURE 2 - The DNA condensation ability of polyallylamines (PAAs) (15 and $65 \mathrm{KDa}$ ) and modified PAAs. DNA condensation measured as a decrease in fluorescence of EtBr, A) PAA $15 \mathrm{KDa}$ derivatives, B) PAA 65 KDa derivatives.

TABLE II - Mean size, PDI, and zeta potential of polyplexes prepared by polyallylamine (PAA) (15 and $65 \mathrm{KDa}$ ) or cholesterol modified PAA/DNA (mean \pm SD, $\mathrm{n}=3$ )

\begin{tabular}{lccc}
\hline Samples & Mean Size $(\mathbf{n m})$ & PDI & Zeta Potential $(\mathbf{m V})$ \\
\hline PAA15 & $161.6 \pm 9.7$ & $0.39 \pm 0.07$ & $19.2 \pm 3.0$ \\
PAA15-5\% & 255.2 & 0.368 & $25.1 \pm 1.9$ \\
PAA15-10\% & $124.0 \pm 7.8$ & $0.34 \pm 0.08$ & $24.6 \pm 1.1$ \\
PAA15-15\% & $308.1 \pm 28.3$ & $0.40 \pm 0.04$ & $28.8 \pm 3.4$ \\
PAA15-30\% & $322.1 \pm 24.9$ & $0.51 \pm 0.06$ & $34.5 \pm 0.5$ \\
PAA15-50\% & $320.8 \pm 20.3$ & $0.58 \pm 0.15$ & $-23.9 \pm 4.3$ \\
PAA65 & $75.4 \pm 20.9$ & $0.43 \pm 0.16$ & $13.3 \pm 1.4$ \\
PAA65-5\% & $533.0 \pm 23.6$ & $0.64 \pm 0.03$ & $-20.5 \pm 1.8$ \\
PAA65-10\% & $372.2 \pm 73.8$ & $0.92 \pm 0.08$ & $-13.9 \pm 2.0$ \\
PAA65-15\% & $344.2 \pm 21.5$ & $0.64 \pm 0.10$ & $-22.1 \pm 2.7$ \\
PAA65-30\% & $371.1 \pm 110.6$ & $0.81 \pm 0.09$ & $-27.5 \pm 0.7$ \\
PAA65-50\% & $414.5 \pm 14.6$ & $0.88 \pm 0.12$ & $-16.7 \pm 6.6$ \\
\hline
\end{tabular}


complete condensation occurred at a higher $\mathrm{C} / \mathrm{P}$ ratio by modification of PAA.

Gene transfer efficiency and cytotoxicity of pDNA polyplexes were evaluated in Neuro2A cells at four different $\mathrm{C} / \mathrm{P}$ ratios as shown in Figures 3 and 4. Generally, transfection efficiency in vectors based PAA $15 \mathrm{kDa}$ increased and in vectors based PAA $65 \mathrm{kDa}$, modification of the polymer with cholesterol did not affect the transfection activity of the vector. The transfection activity of polyplexes composed of PAA $15 \mathrm{kDa}$ was higher than PAA $65 \mathrm{kDa}$. The highest gene transfer ability belonged to PAA $15 \mathrm{kDa}$ modified with $10 \%$ cholesterol at $\mathrm{C} / \mathrm{P}$ ratio of 4 .

The effect of conjugation of PAA with cholesterol on cytotoxicity was examined on Neuro2A cells using the MTT assay. The cytotoxicity of PAA decreased remarkably by covering the amine groups of the polymer, especially in the higher C/P. It can be seen that the
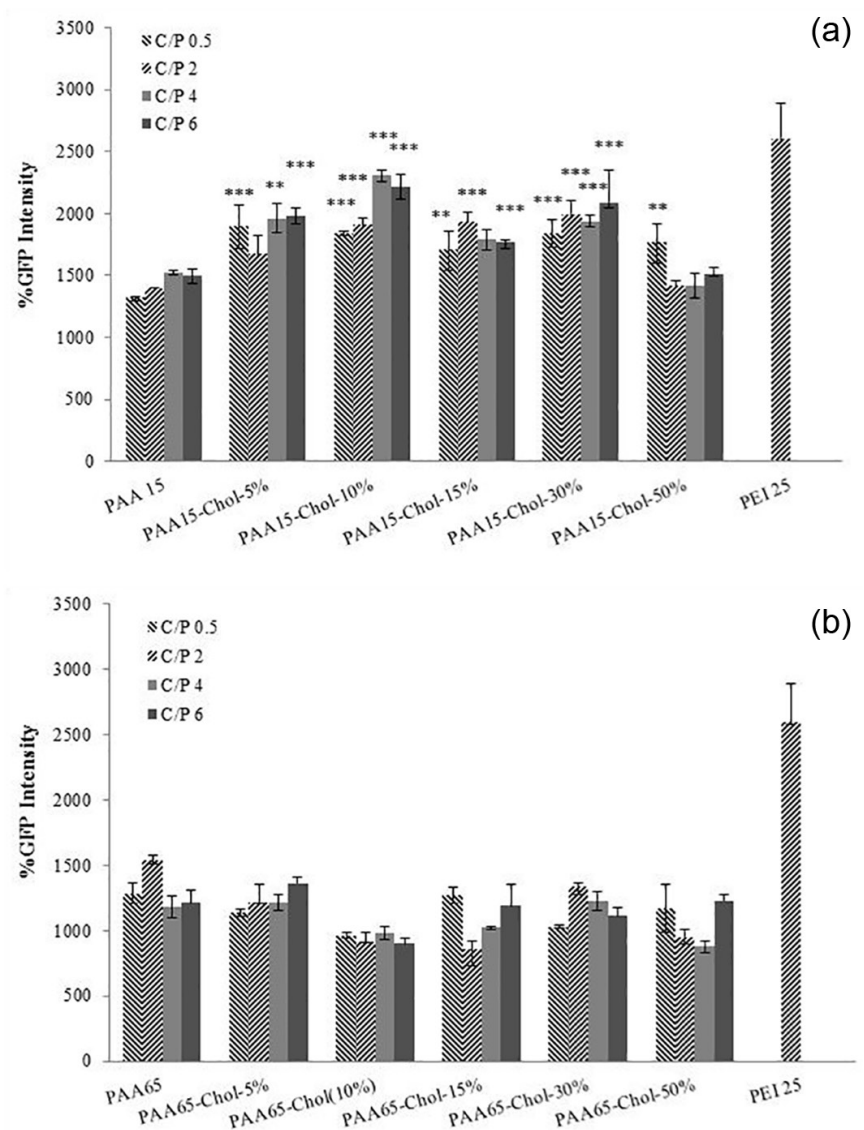

FIGURE 3 - Transfection activity of polyplexes prepared by polyallylamine (PAA) (15 and $65 \mathrm{KDa}$ ) or cholesterol modified PAA in Neuro2A cells. Complexes were formulated at three different C/P ratios, A) PAA $15 \mathrm{KDa}$ derivatives, B) PAA 65 KDa derivatives. Comparison was made between cholesterol modified PAAs and unmodified PAA, ${ }^{* *}: \mathrm{p}<0.01,{ }^{* * *}: \mathrm{p}<0.001$ (mean $\pm \mathrm{SD}, \mathrm{n}=3$ ).
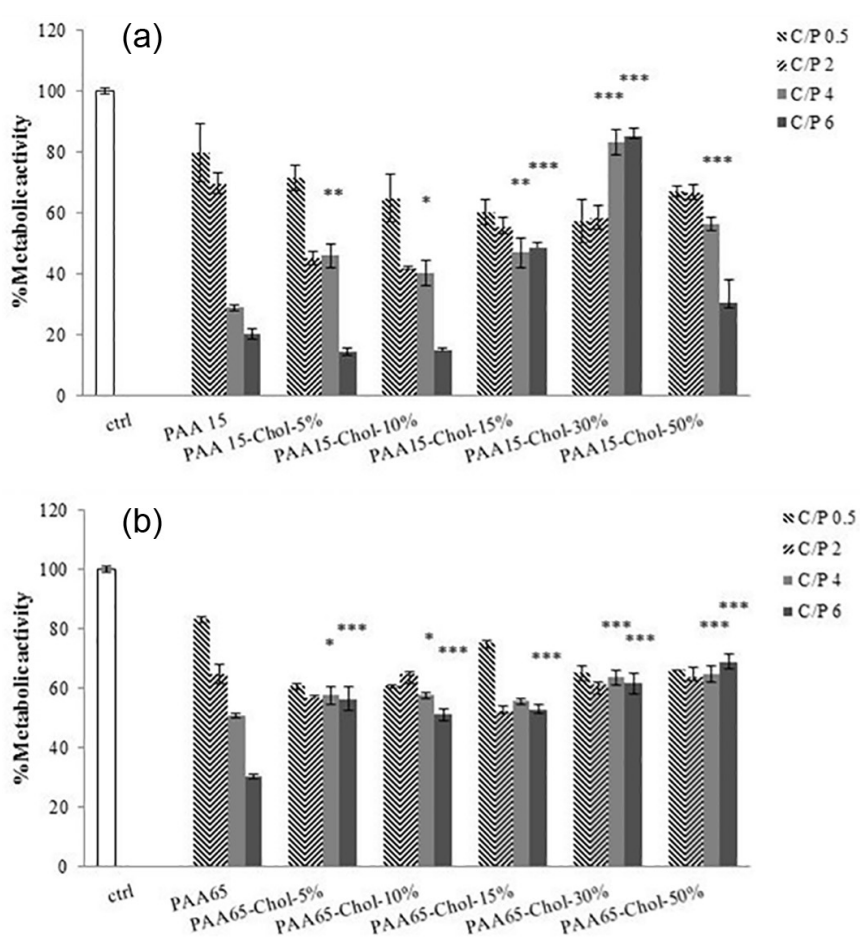

FIGURE 4 - Cytotoxicity of polyplexes prepared by polyallylamine (PAA) (15 and $65 \mathrm{KDa}$ ) or cholesterol modified PAA at different C/P ratios, A) PAA 15 KDa derivatives, B) PAA $65 \mathrm{KDa}$ derivatives. Comparison was made between cholesterol modified PAAs and unmodified PAA, *: $\mathrm{p}<0.05, * *$ : $\mathrm{p}<0.01$, $* * *: \mathrm{p}<0.001($ mean $\pm \mathrm{SD}, \mathrm{n}=3)$.

cytotoxicity of synthetic vectors in $\mathrm{C} / \mathrm{P} 4$ was less toxic than the unmodified PAA. It can be concluded that PAA toxicity may be alleviated by cholesterol modifications.

\section{DISCUSSION}

Gene therapy is a promising approach toward acquired or inherited disease treatment (Smith, 1999; Romano et al., 2000). To be applied in vitro, it is vital for gene delivery vectors to be efficient in transfection activity with low toxicity (Hasegawa, Hirashima, Nakanishi, 2002). Some features including low immunogenicity and toxicity, ease of development, and lack of pathogenicity have particularly attracted more attention to non-viral vectors (Putnam, 2006; Li, Huang, 2006). However, in comparison to viral vectors, non-viral vector low transfection efficiency is introduced as the main drawback of these carriers (Tros-de-Ilarduya, Sun, Duzgunes, 2010).

Polyallylamine (PAA) has recently drawn much attention as a non-viral gene delivery system (Pathak et al., 2007; Oskuee et al., 2015b, Mahmoudi et al., 2014). Low buffering capacity and prevention of easy endosomal escape are introduced as the main disadvantages of this 
polymer (Pathak, Patnaik, Gupta, 2009). If cationic polymers such as PAA are used without any chemical modification, they possess high cytotoxicity index (Gholami et al., 2014). Also, they usually require lysosomotropic agents or some modifications to improve endocytosis in order to achieve efficient gene transfer (Pathak et al., 2007). As an instance, Neu, Fischer, and Kissel (2005) argue that PAA interaction with endosome membranes improves and endosomal escape possibility increases if hydrophobic groups are used in the polymer structure. In the present study, primary amine groups of PAA with two molecular weights (15 and $65 \mathrm{kDa})$ were modified with cholesterol in five grafting percentages $(5,10,15,30$, and 50) to enhance hydrophobicity. High transfection activity and low toxicity are the main justification criteria for cationic derivatives application (Hasegawa, Hirashima, Nakanishi, 2002; Hattori, Maitani, 2007). Since cholesterol exists in the human body, its use in gene therapy is harmless. As indicated by the results of the previous study, polyethyleneimine (PEI)- cholesterol joined through a carbamate linkage are nontoxic and biodegradable (Kim et al., 2001). Although DNA and PAA have high aqueous solubility, due to lipophilic nature of cholesterol, the synthesized polymers showed lower aqueous solubility compared to PAA alone. As grafting percent increases, modified polymer aqueous solubility decreases.

The ability of carriers in DNA condensation is assessed through the ethidium bromide test. As indicated by Oskuee et al. (2015a), the interaction between polymer positive charge and plasmid negative charge causes condensation. According to the results of the present study, unmodified PAA is more capable of DNA condensation, since primary amines of PAA are not surrounded by cholesterol. It is indicated that increasing grafting percent reduces modified polymer condensation ability, which is caused by the presence of voluminous amount of cholesterol. Therefore, DNA condensation happened through a higher $\mathrm{C} / \mathrm{P}$ ratio.

Cellular uptake is heavily influenced by some factors such as surface charge and particle size. The effectiveness of transfection efficiency in polyplexes depends on particle size (Almofti et al., 2003; Zaric et al., 2004). In the present study, polyplexes in the 125 to $530 \mathrm{~nm}$ size range were formed by synthesized polymers. It is reported that as grafting percent increases, the size of polyplexes increases. According to the results of the previous study in the same field, compared to the unmodified PAA, the size of the polyplex increases as polymer hydrophobicity increases. Forrest, Koerber, and Pack (2003) suggest that reduced protonated ability makes binding polymers modified by
DNA weaker, resulting in lower compact complexes. As reported by Rejman et al. (2004), particles with the size of $500 \mathrm{~nm}$ enter through non-phagocytic paths. On the other hand, smaller than $200 \mathrm{~nm}$ particles enter through clathrinmediated endocytosis while $200-500 \mathrm{~nm}$ particles enter into the cell through the caveolae-mediated endocytosis path. Finally, as Khalil et al. (2006) argue, larger than 500 $\mathrm{nm}$ particles entering through phagocytosis have low gene delivery efficiency. As far as the vectors of this study are concerned, particle size was in the 125 to $500 \mathrm{~nm}$ range making uptake occur through the caveolae-mediated endocytosis. Lysosomic decomposition, in this pathway, does not affect the polyplexes route. Therefore, Khalil et al. (2006) argue that this path is a useful gene delivery route. Moreover, Kim et al. (2006) reported that the binding of cholesterol to specific serum ligands increases the rate of polyplex entrance into the cell by ligandmediated endocytosis. Oskuee et al. (2008) emphasized that compact and positively charged particles can interact more effectively with lipid bilayer membranes resulting in more efficient transfection. The results of the study report that transfection efficiency increases in vector-based PAA15 kDa enhanced by increased grafting percentage. Vector lipophilicity increase caused by cholesterol addition resulting in enhanced vector cellular uptake may be the main reason for transfection efficiency increase. Vector suitable buffering capacity and favorable hydrophobichydrophilic balance cause transfection efficiency variation after PAA modification with cholesterol (Oskuee et al., 2015a, Oskuee et al., 2008).

As indicated by the results of the present study, low grafting percentages made transfection rate increase while in $50 \%$ replaced carrier, no significant difference was evident between transfection efficiency of modified PAA and PAA15 kDa. Zintchenko et al. (2008) reported similar results for PEI modified with propionic acid or succinic acid. Thomas et al. (2005) argue that transfection ability is reduced if polycation positive charge is highly reduced while in previous studies, Oskuee et al. (2015b) concluded that polyplex transfection activity was not influenced by hydrophobic-modified PAA65 kDa. Additionally, according to the results of the present study regarding transfection efficiency, there is no significant difference between cholesterol modified PAA $65 \mathrm{kDa}$ and the unmodified one. It should be noted that transfection is a cell-dependent procedure and the reason we employed the Neuro2a cell line is that it is hardly transfectable so if the newly synthesized vector could transfect it well, getting similar results with other cell lines is highly probable, however, other cell lines could be used in the transfection to make it possible to generalize the current data. 
Considering the limitations of measurement of the mitochondrial metabolic activity (MTT assay) in evaluating different aspects of toxicity raised by vectors, it was observed that in both molecular weights, polymer modification reduced viability significantly. As shown by viability profile, grafting percentage increase led to cytotoxicity reduction. Evidently, negatively charged cholesterol groups placement is the main reason for PAA toxicity reduction. According to Kim et al. (2001), the toxicity of polyplex embedded with PEI-cholesterol is reduced by cholesterol, and cell viability increase is remarkably affected by cholesterol percentage increase. PAA $65 \mathrm{kDa}$ was more toxic than PAA $15 \mathrm{kDa}$. Hunter (2006) pointed out that polyplex with high positive charge results in interaction with the cell membrane causing damage to the cell.

\section{CONCLUSION}

A series of vectors based on PAA $15 \mathrm{kDa}$ and $65 \mathrm{kDa}$ were successfully synthesized. The results of transfection study showed that modified polymer composed of PAA $(15 \mathrm{kDa})$ modified with cholesterol in $10 \%$ grafting is a suitable vector for gene delivery with low cytotoxicity.

\section{ACKNOWLEDGMENTS}

This study was supported by a grant from the Vice Chancellor for Research of Mashhad University of Medical Science, Mashhad, Iran. Authors declare that there is no conflict of interests in this study. The results presented in this paper were part of a PharmD student thesis.

\section{REFERENCES}

Almofti MR, Harashima H, Shinohara Y, Almofti A, Li W, Kiwada H. Lipoplex size determines lipofection efficiency with or without serum. Mol Membr Biol. 2003;20(1):35-43.

Boussif O, Delair T, Brua C, Veron L, Pavirani A, Kolbe HV. Synthesis of polyallylamine derivatives and their use as gene transfer vectors in vitro. Bioconjug Chem. 1999;10(5):877-883.

Chesnoy S, Huang L. Structure and function of lipid-DNA complexes for gene delivery. Annu Rev Biophys Biomol Struct. 2000;29:27-47.

Cusack JR JC, Tanabe KK. Introduction to cancer gene therapy. Surg Oncol Clin. 2002;11(3):497-519.
Dehshahri A, Sadeghpour H, Kazemi Oskuee R, Sabahi Z, Fadaei M, Hossaini Alhashemi S, et al. Interleukin-12 plasmid DNA delivery using L-thyroxine-conjugated polyethylenimine nanocarriers. J Nanopart Res. 2014;16:1-14.

El-Aneed A. An overview of current delivery systems in cancer gene therapy. J Control Release 2004;94(1):1-14.

Forrest ML, Koerber JT, Pack DW. Degradable polyethylenimine derivative with low toxicity for highly efficient gene delivery. Bioconjug Chem. 2003;14(5):934-940.

Gholami L, Sadeghnia HR, Darroudi M, Kazemi Oskuee R. Evaluation of genotoxicity and cytotoxicity induced by different molecular weights of polyethylenimine/DNA nanoparticles. Turk J Biol. 2014;38:380-387.

Guo XD, Tandiono F, Wiradharma N, Khor D, Tan CG, Khan $\mathrm{M}$, et al. Cationic micelles self-assembled from cholesterolconjugated oligopeptides as an efficient gene delivery vector. Biomaterials. 2008;29(36):4838-4846.

Hasegawa S, Hirashima N, Nakanishi M. Comparative study of transfection efficiency of cationic cholesterols mediated by liposomes-based gene delivery. Bioorg Med Chem. 2002;12(9):1299-1302.

Hattori Y, Maitani Y. Low-molecular-weight polyethylenimine enhanced gene transfer by cationic cholesterol-based nanoparticle vector. Biol Pharm Bull. 2007;30(9):1773-1778.

Hunter AC. Molecular hurdles in polyfectin design and mechanistic background to polycation induced cytotoxicity. Adv Drug Deliv Rev. 2006;58(14):1523-1531.

Khalil IA, Kogure K, Akita H, Harashima H. Uptake pathways and subsequent intracellular trafficking in nonviral gene delivery. Pharmacol Rev. 2006;58(1):32-45.

Kim S, Choi JS, Jang HS, Suh H, Park J. Hydrophobic modification of polyethyleneimine for gene transfectants. Bull Korean Chem Soc. 2001;22(10):1069-1075.

Kim WJ, Christensen LV, Jo S, Yockman JW, Jeong JH, Kim YH, Kim SW. Cholesteryl oligoarginine delivering vascular endothelial growth factor siRNA effectively inhibits tumor growth in colon adenocarcinoma. Mol Ther. 2006;14(3):343350 .

Li S, Huang L. Nonviral gene therapy: promises and challenges. Gene Ther. 2000;7(1):31-34. 
Li SD, Huang L. Gene therapy progress and prospects: non-viral gene therapy by systemic delivery. Gene Ther. 2006;13(18):1313-1319.

Liu F, Huang L. Development of non-viral vectors for systemic gene delivery. J Control Release. 2002;78(1-3):259-266.

Mahmoudi A, Oskuee RK, Ramezani M, Malaekeh-Nikouei B. Preparation and in-vitro transfection efficiency evaluation of modified cationic liposome-polyethyleneimine-plasmid nanocomplexes as a novel gene carrier. Curr Drug Deliv. 2014;11(5):636-642.

Merdan T, Kopecek J, Kissel T. Prospects for cationic polymers in gene and oligonucleotide therapy against cancer. Adv Drug Deliv Rev. 2002;54(5):715-758.

Neu M, Fischer D, Kissel T. Recent advances in rational gene transfer vector design based on poly(ethylene imine) and its derivatives. J Gene Med. 2005;7(8):992-1009.

Nimesh S, Kumar R, Chandra R. Novel polyallylamine-dextran sulfate-DNA nanoplexes: Highly efficient non-viral vector for gene delivery. Int J Pharm. 2006;320(1-2):143-149.

Oskuee RK, Dehshahri A, Shier WT, Ramezani M. Modified polyethyleneimine: self assemble nanoparticle forming ploymer for pDNA delivery. Iran J Basic Med Sci. 2008;11(1):33-40.

Oskuee RK, Dosti F, Gholami L, Malaekeh-Nikouei B. A simple approach for producing highly efficient DNA carriers with reduced toxicity based on modified polyallylamine. Mater Sci Eng C Mater Biol Appl. 2015b;49:290-296.

Oskuee RK, Zakeri V, Gholami L, Malaekeh-Nikouei B. Preparation, characterization and transfection efficiency of nanoparticles composed of bromoalkane modified polyallylamine. Nanomed J. 2015a;2(2):111-120.

Pathak A, Aggarwal A, Kurupati RK, Patnaik S, Swami A, Singh $\mathrm{Y}$, et al. Engineered polyallylamine nanoparticles for efficient in vitro transfection. Pharm Res. 2007;24(8):1427-1440.
Pathak A, Patnaik S, Gupta KC. Recent trends in non-viral vector-mediated gene delivery. Biotech J. 2009;4(11):15591572 .

Putnam D. Polymers for gene delivery across length scales. Nat Mater. 2006;5:439-451.

Rejman J, Obevle V, Zuhom IS, Hockstar D. Size-dependent internalization of particle via the pathways of clothrin and caveoline-mediated endocytosis. Biochem J. 2004;377(Pt 1):159-169.

Romano G, Micheli P, Pacilio C, Giordano A. Latest developments in gene transfer technology: achievements, perspectives, and controversies over therapeutic applications. Stem Cells. 2000;18(1):19-39.

Smith AE. Gene therapy-where are we? Lancet. 1999;354:S1S4.

Snyder SL, Sobocinski PZ. An improved 2, 4, 6-trinitrobenzenesulfonic acid method for the determination of amines. Anal Biochem. 1975;64(1):284-288.

Thomas M, Lu JJ, Ge O, Zhang C, Chen J, Klibanov AM. Full deacylation of polyethylinimin deramatically boosts its gene delivery efficiency and specificity and specificity to mouse lung. Proc Natl Acad Sci USA. 2005;102(16):5679-5684.

Tros-de-Ilarduya C, Sun Y, Duzgunes N. Gene delivery by lipoplexes and polyplexes. Eur J Pharm Sci. 2010;40(3):159170.

Zaric V, Weltin D, Erbacher P, Remy JS, Behr JP, Stephan D. Effective polyethylenimine-mediated gene transfer into endothelial cells. J Gene Med. 2004;6(2):176-184.

Zintchenko A, Philipp A, Dehshahri A, Wagner E. Simple modifications of branched PEI lead to highly efficient siRNA carriers with low toxicity. Bioconjug Chem. 2008;19(7):14481455 . 